\title{
Genetic and environmental control of host-gut microbiota interactions
}

\author{
Elin Org, ${ }^{1}$ Brian W. Parks, ${ }^{1}$ Jong Wha J. Joo, ${ }^{2}$ Benjamin Emert, ${ }^{1}$ William Schwartzman, ${ }^{1}$ \\ Eun Yong Kang, ${ }^{3}$ Margarete Mehrabian, ${ }^{1}$ Calvin Pan, ${ }^{4}$ Rob Knight, ${ }^{5}$ Robert Gunsalus, ${ }^{6}$ \\ Thomas A. Drake, ${ }^{7}$ Eleazar Eskin, ${ }^{3,4}$ and Aldons J. Lusis ${ }^{1,4,8}$ \\ ${ }^{1}$ Department of Medicine/Division of Cardiology, David Geffen School of Medicine, University of California, Los Angeles, \\ California 90095, USA; ${ }^{2}$ Bioinformatics IDP, University of California, Los Angeles, California 90095, USA; ${ }^{3}$ Department of Computer \\ Science, University of California, Los Angeles, California 90095, USA; ${ }^{4}$ Department of Human Genetics, David Geffen School of \\ Medicine, University of California, Los Angeles, California 90095, USA; ${ }^{5}$ Departments of Pediatrics and Computer Science and \\ Engineering, University of California, San Diego, California 92093, USA; ${ }^{6}$ Department of Microbiology, Immunology and Molecular \\ Genetics, University of California, Los Angeles, California 90095, USA; ${ }^{7}$ Department of Pathology and Laboratory Medicine, \\ University of California, Los Angeles, California 90095, USA; ${ }^{8}$ Department of Microbiology, Immunology and Molecular Genetics, \\ University of California, Los Angeles, California 90095, USA
}

\begin{abstract}
Genetics provides a potentially powerful approach to dissect host-gut microbiota interactions. Toward this end, we profiled gut microbiota using $16 \mathrm{~s}$ rRNA gene sequencing in a panel of 110 diverse inbred strains of mice. This panel has previously been studied for a wide range of metabolic traits and can be used for high-resolution association mapping. Using a SNPbased approach with a linear mixed model, we estimated the heritability of microbiota composition. We conclude that, in a controlled environment, the genetic background accounts for a substantial fraction of abundance of most common microbiota. The mice were previously studied for response to a high-fat, high-sucrose diet, and we hypothesized that the dietary response was determined in part by gut microbiota composition. We tested this using a cross-fostering strategy in which a strain showing a modest response, SWR, was seeded with microbiota from a strain showing a strong response, $A \times B 19$. Consistent with a role of microbiota in dietary response, the cross-fostered SWR pups exhibited a significantly increased response in weight gain. To examine specific microbiota contributing to the response, we identified various genera whose abundance correlated with dietary response. Among these, we chose Akkermansia muciniphila, a common anaerobe previously associated with metabolic effects. When administered to strain A×B19 by gavage, the dietary response was significantly blunted for obesity, plasma lipids, and insulin resistance. In an effort to further understand host-microbiota interactions, we mapped loci controlling microbiota composition and prioritized candidate genes. Our publicly available data provide a resource for future studies.
\end{abstract}

[Supplemental material is available for this article.]

Studies carried out over the last decade have revealed that gut microbiota contribute to a variety of common disorders, including obesity and diabetes (Musso et al. 2011), colitis (Devkota et al. 2012), atherosclerosis (Wang et al. 2011), rheumatoid arthritis (Vaahtovuo et al. 2008), and cancer (Yoshimoto et al. 2013). The evidence for metabolic interactions is particularly strong, as a large body of data now supports the conclusion that gut microbiota influence the energy harvest from dietary components, particularly complex carbohydrates, and that metabolites such as the shortchain fatty acids produced by gut bacteria can perturb metabolic traits, including adiposity and insulin resistance (Turnbaugh et al. 2006, 2009; Backhed et al. 2007; Wen et al. 2008; Ridaura et al. 2013). Gut microbiota communities are assembled each generation, influenced by maternal seeding, environmental factors, host genetics, and age, resulting in substantial variations in composition among individuals in human populations (Eckburg et al. 2005; Costello et al. 2009; Human Microbiome Project

\section{Corresponding author: jlusis@mednet.ucla.edu}

Article published online before print. Article, supplemental material, and publication date are at http://www.genome.org/cgi/doi/10.1101/gr.194118.115. Freely available online through the Genome Research Open Access option.
Consortium 2012; Goodrich et al. 2014). Most experimental studies of host-gut microbiota interactions have employed large perturbations, such as comparisons of germ-free versus conventional mice, and the significance of common variations in gut microbiota composition for disease susceptibility is still poorly understood. Furthermore, while studies with germ-free mice have clearly implicated microbiota in clinically relevant traits, it has proven difficult to identify the responsible taxa of bacteria.

We now report a population-based analysis of host-gut microbiota interactions in the mouse. One of the issues we explore is the role of host genetics. Although some evidence is consistent with significant heritability of gut microbiota composition, the extent to which the host controls microbiota composition under controlled environmental conditions is unclear. We also examined the role of common variations in gut microbiota in metabolic traits such as obesity and insulin resistance and mapped loci contributing to the abundance of certain microbiota. We performed our study using a resource termed the Hybrid Mouse Diversity Panel (HMDP), consisting of about 100 inbred strains of mice that

(c) 2015 Org et al. This article, published in Genome Research, is available under a Creative Commons License (Attribution 4.0 International), as described at http://creativecommons.org/licenses/by/4.0/. 
have been either sequenced or subjected to high-density genotyping (Bennett et al. 2010). The resource has several advantages for genetic analysis as compared to traditional genetic crosses. First, it allows high-resolution mapping by association rather than linkage analysis, and it has now been used for the identification of a number of novel genes underlying complex traits (Farber et al. 2011; Lavinsky et al. 2015; Parks et al. 2015; Rau et al. 2015). Second, since the strains are permanent, the data from separate studies can be integrated, allowing the development of large, publicly available databases of physiological and molecular traits relevant to a variety of clinical disorders (systems.genetics.ucla.edu and phenome.jax.org). Third, the panel is ideal for examining gene-by-environment interactions, since it is possible to examine individuals of a particular genotype under a variety of conditions (Orozco et al. 2012; Parks et al. 2013).

\section{Results}

\section{Variation of gut microbiota in a large panel of mouse strains}

We determined the composition and variability of gut microbiota in a total of 599 mice from 113 HMDP strains, of which 327 were male and 273 were female (average three mice per strain) (Supplemental Table 1). All mice in the study were bred for two or more generations in the same facility at UCLA, and each strain was maintained in separate cages (two to four mice of each strain). The mice were maintained on a chow diet ( $6 \% \mathrm{kcal}$ from fat) until 8 wk of age, and then placed on a high-fat, high-sucrose (HF/HS) diet for anadditional $8 \mathrm{wk}$. We performed multiplex $16 \mathrm{~S}$ rRNA sequencing of the V4 amplicon using the Illumina MiSeq platform. On average, 23,048 reads were obtained per sample (ranging from 6331 to 82,238 ). Reads were binned into individual samples based on barcode sequence, and complementary taxon-based analysis methods were used to compare $16 \mathrm{~S}$ rRNA sequences across the cecum microbial communities. The relative abundances of phylum, class, order, family, and genus were determined for the 599 mice. We focused on abundant microbes, defined as operational taxonomic units (OTUs) with at least $0.01 \%$ relative abundance across all samples (total 439 OTUs).

We previously showed that changing a chow to a HF/HS diet drastically changed microbiota composition across HMDP strains and that these shifts were strongly dependent on the genetic background of the mice (Parks et al. 2013). After HF/HS diet feeding, we identified 49 genera, where the 17 most abundant genera were present in at least $75 \%$ of the samples $(n=$ 599). These seventeen most abundant genera accounted for $68 \%$ of reads and included members of the six phyla (Supplemental Table 2). Consistent with previous findings in both mice and humans, the most abundant phyla in the gut were Firmicutes $(49.8 \% \pm 10.9)$ and Bacteroidetes $(41.8 \% \pm 9.6)$. Compared to the chow diet, the HF/HS diet resulted in increased Firmicutes and decreased Bacteroidetes, consistent with previous studies (Wu et al. 2011; Carmody et al. 2015).

Microbiota composition varied greatly across the 110 strains of mice
(Fig. 1A; Supplemental Table 2). For instance, the relative abundance of the Firmicutes across all the strains ranged between $20 \%$ and $82 \%$. Even larger variations were observed at finer taxonomic levels; for example, a common mucus layer inhabitant in gut, Akkermansia muciniphila (A. muciniphila), varied in abundance from $0.005 \%$ to $40 \%$ across the strains of mice. In contrast to human data, we were not able to detect any members of hydrogen-consuming methanogens, although not all methanogens, which are Archaea, would be expected to amplify with bacterial 16S RNA gene primers.

\section{Heritability estimation of gut microbiota composition}

In examining individual mice housed in separate cages (to avoid cage effects since mice are coprophagic), we found that microbiota compositions were much more similar within strains than between strains $(P<0.001$ for unweighted and weighted UniFrac) (Fig. 1B; Supplemental Fig. 1). However, because the members of an inbred strain share a recent common ancestor, it is unclear to what extent the shared microbiota result from parent to offspring transfer of microbiota as compared to host genetic factors. The standard ways to estimate heritability, defined in an outbred population as the proportion of the phenotypic variance contributed by the genetic variance (Falconer and Mackay 1996; Lynch and Walsh 1998), are to examine pedigrees or compare monozygotic with di-zygotic twins. In mice, this is traditionally done using inter-crosses between strains differing in traits of interest. Because of the problem of maternal seeding, we estimated heritability by a different method, based on the proportion of phenotype variance accounted for by genetic relationships among the strains.

All of the HMDP strains have been either sequenced or densely genotyped (http://www.jax.org), allowing us to determine their genetic relatedness. Based on this SNP-based approach (rather than a family-based approach), we were able to estimate the heritability of the abundance of the major taxa of gut microbiota (Supplemental Table 3). For the calculation, we utilized a linear mixed model and assumed additive effects (see Methods). The assumption behind the linear mixed model approach is that the covariance of the genetic component of the phenotypic data is proportional to the kinship matrix or genetic similarity matrix between the animals. In this model, each individual mouse microbiome composition
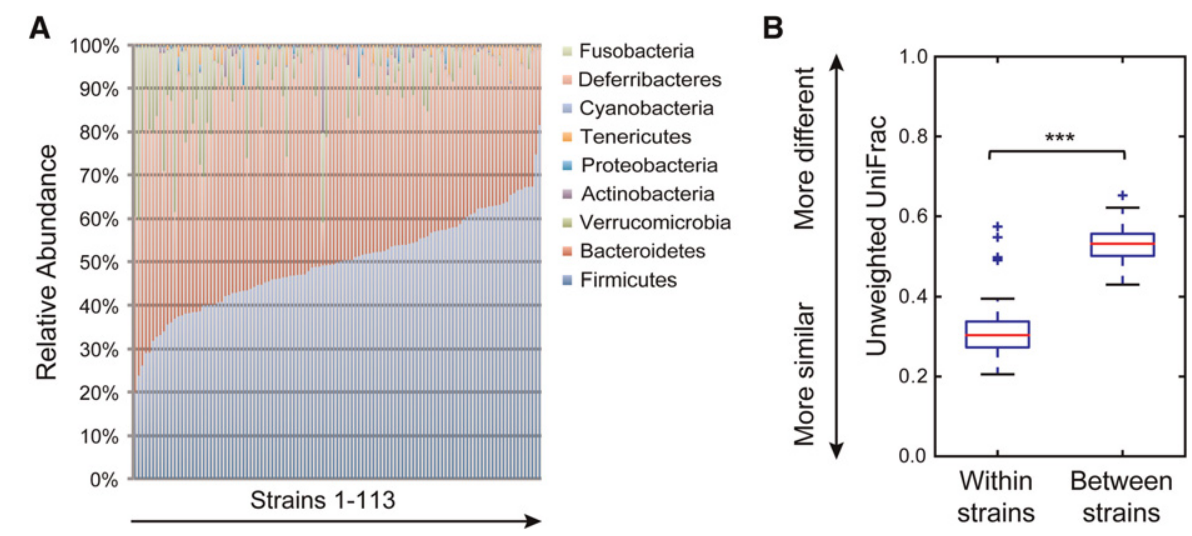

Figure 1. Phylum-level variability of gut microbiota composition across 113 inbred strains of mice. $(A)$ Columns represent the relative abundance of microbial phyla in 113 strains (327 male and 297 female). (B) Box plot of $\beta$ diversity distances between microbial communities obtained when comparing mice within and between strains. The specific distance metric used is indicated on the axes. $\left({ }^{* * *}\right) P<0.001$ for Student's $t$-test with 1000 Monte Carlo simulations. See also Supplemental Table 2. 
(relative abundance of each taxa) is affected by a genetic random effect, which is correlated across mice by virtue of sharing some of the genetic variants affecting microbiome, and an environmental random effect, which is uncorrelated across mice.

When maintained under controlled conditions, host genetic variation appears to explain a substantial amount of the variation in gut microbiota composition in the HMDP, up to 0.5 or more for many common taxa (Table 1; Supplemental Table 3). The range of heritabilities of microbiota was similar for phyla, families, and genera, and for males and females (Supplemental Table 3) and approached the range of heritabilities we observed for measured clinical phenotypes (Supplemental Table 4).

Our approach for estimating the heritability of gut microbiota composition is potentially confounded by the complication of physical transmission (Ubeda et al. 2012; McCafferty et al. 2013). However, since most of the inbred strains have been separated for many decades, it seems unlikely that a particular composition would be maintained over so many generations if it was due largely to physical "seeding." A second possible caveat in this analysis is that multiple animals from the same strain were, in some cases, housed in the same cage, and they may share similar microbiota compositions due to physical transfer rather than host genotype. We rule out this confounding factor by performing the same analysis using only one animal per strain (Supplemental Table 3). We expected lower heritability than in the complete cohort because of reduced total genetic relatedness and power. However, even in the reduced sample, while our estimates are lower than the complete data set, host genotype still accounts for a substantial fraction of the variation.

\section{Gut microbiota contribute to dietary responsiveness}

Among the HMDP strains examined were striking differences in response to the HF/HS diet. Some strains showed as much as a sixfold increase in body fat whereas others showed no significant change, and food consumption was only modestly associated with the gain in body weight $\left(r^{2}=0.30\right)$ or the gain in fat mass $\left(r^{2}=0.04\right)$ (Parks et al. 2013). Likewise, HOMA-IR, a measure of insulin resistance, showed over a 50-fold range among the strains (Parks et al. 2015). We hypothesized that the composition of the gut microbiota might contribute to this variation.

To test the hypothesis, we performed neonatal cross-fostering experiments between two strains, $\mathrm{A} \times \mathrm{B} 19$ and SWR, exhibiting

Table 1. Heritability estimates for gut microbiota in HMDP strains

\begin{tabular}{lc}
\hline Taxa & Heritability \% \\
\hline Rikenellaceae; unknown & 54 \\
S24-7; unknown & 60 \\
Lactococcus spp. & 31 \\
Turicibacter spp. & 54 \\
Clostridiaceae; unknown & 61 \\
Lachnospiraceae; unknown & 56 \\
Coprococcus spp. & 28 \\
Roseburia spp. & 33 \\
Ruminococcus gnavus & 48 \\
Peptostreptococcaceae; unknown & 49 \\
Ruminococcaceae; unknown & 39 \\
Oscillospira spp. & 53 \\
Ruminococcus spp. & 35 \\
Mogibacteriaceae; unknown & 26 \\
Erysipelotrichaceae; unknown & 65 \\
Akkermansia muciniphila & 54 \\
\hline
\end{tabular}

See also Supplemental Table 3. diverse responses after HF/HS feeding. Figure 2A shows the response of the two strains to the diet in terms of body fat increase during $8 \mathrm{wk}$ of $\mathrm{HF} / \mathrm{HS}$ diet feeding. The $\mathrm{A} \times \mathrm{B} 19$ strain gained $\sim 24 \mathrm{~g}$ fat in response to the diet while strain SWR gained $\sim 4 \mathrm{~g}$ (Fig. 2A; Supplemental Fig. 2A). We cross-fostered newborn SWR mice with $\mathrm{A} \times \mathrm{B} 19$ dams and observed that the gut microbiota composition of the cross-fostered pups resembled $\mathrm{A} \times \mathrm{B} 19$ mice rather than SWR mice, indicating efficient transfer (Fig. 2B). At 4 wk of age, we placed the pups on the HF/HS diet and monitored fat gain. In a pilot study (Supplemental Fig. 2B), both cross-fostered male and female mice initially exhibited increased weight gain as compared to SWR mice. While the male mice continued to show an increased response up to $8 \mathrm{wk}$ on the diet, the female mice became similar to SWR mice after $8 \mathrm{wk}$. We then repeated the study with a larger group of cross-fostered mice $(n=8-11$ per group). Again, the male cross-fostered mice showed significantly more weight gain and higher body fat composition $(P<0.01)$ as compared to SWR control mice (Fig. 2C,D). In addition, cross-fostered male SWR mice also showed higher levels of plasma triglyceride compared to SWR mice (Fig. 2E). The female mice, on the other hand, did not exhibit a significant increase in body fat at 8 wk of age (Supplemental Fig. 2C). After 8 wk of the HF/HS diet, the microbiota composition of the cross-fostered SWR pups moved back toward SWR microbiota composition, supporting the role of host genotype in microbiota community structure (Fig. 2F). We conclude that common variations in the composition of the gut microbiome contribute in part to the response to a HF/HS diet.

\section{Gut microbiota associations with metabolic and cardiovascular traits}

To identify which bacteria contribute to obesity and metabolic phenotypes, we sought to identify potential relationships between metabolic traits and the gut microbiota. Altogether, we identified many correlations, including some novel and some known relationships (Supplemental Table 5). Several of these appear to be significant, based on a false discovery rate of $<0.01$.

Two taxa from the family Lachnospiracea, Roseburia spp. and Ruminococcus gnavus, were positively associated with obesity and metabolic traits including body fat increase on a HF/HS diet, insulin levels, and HOMA-IR $(P<0.001)$. The same traits were also associated with an unknown species of Lactobacillus (Supplemental Table 5). Our data are consistent with a recent study, showing that increased abundance of Roseburia spp. in obese subjects is positively correlated with body mass index and inflammation (Tims et al. 2013; Verdam et al. 2013), and Lactobacillus reuteri has been previously linked to increased obesity in humans (Million et al. 2012). A. muciniphila was inversely correlated with body fat $\left(r=-0.15 ; P=9.02 \times 10^{-4}\right)$ and insulin levels $(r=-0.20 ; P=4.57 \times$ $10^{-6}$ ) (Supplemental Table 5). A. muciniphila is a mucin-degrading, gram-negative anaerobe residing in intestinal mucus layers that has been associated with obesity and insulin resistance in humans and mice (Derrien et al. 2011; Everard et al. 2013).

\section{Akkermansia muciniphila treatment improves obesity and metabolic parameters in mice fed a high-fat/high-sucrose diet}

To test causality of the relationship, we administrated live or heatkilled A. muciniphila to obesity-prone A×B19 male mice (Supplemental Fig. 3A). Ten-week-old male $\mathrm{A} \times \mathrm{B} 19$ mice were treated five times per week with $A$. muciniphila by oral gavage at a dose of $1.44 \times 10^{9} \mathrm{cfu} / 0.2 \mathrm{~mL}$ (HF/HS-Akk), while control mice were treated with an oral gavage of an equivalent volume of heat-killed

\section{Genome Research}

www.genome.org 
A

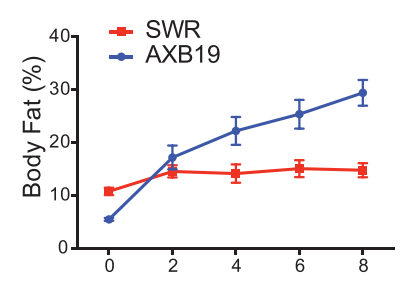

C

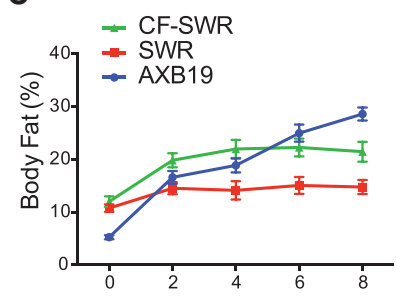

E

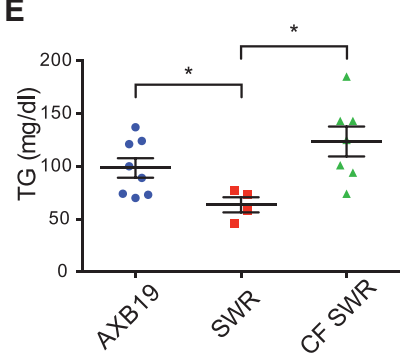

B

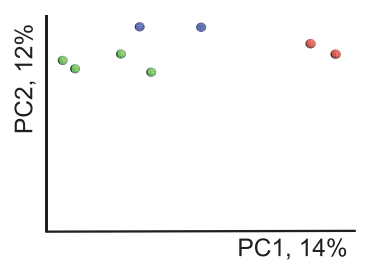

D

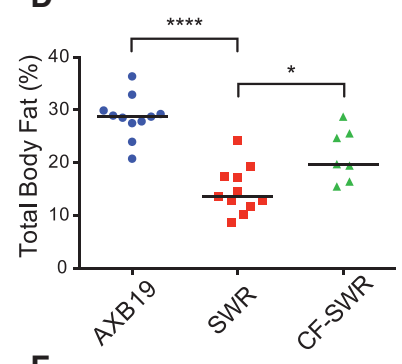

$\mathbf{F}$

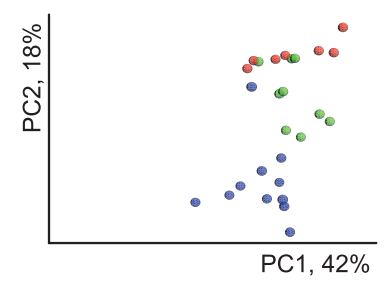

Figure 2. Cross-fostering influences dietary responsiveness. $(A)$ Body fat increase in SWR and $\mathrm{A} \times \mathrm{B} 19$ strains during $8 \mathrm{wk}$ of the HF/HS diet. (B) Principal Coordinate Analysis (PCoA) of unweighted UniFrac distances for fecal samples after cross-fostering newborn SWR and A×B19 pups between parents (blue $=A \times B 19$ mothers, red $=$ SWR mothers, and green $=$ cross-fostered SWR pups), $P<0.05$ for unweighted UniFrac using Student's $t$-test with 1000 Monte Carlo simulations. (C) Body fat changes after cross-fostering SWR pups with A×B19 mother (CF-SWR) compared to SWR and A $\times$ B19 controls. (D) Total body fat percentage after 8 wk of HF/ $\mathrm{HS}$ feeding. ( $E$ ) Plasma triglycerides (TG) levels. $(F)$ PCoA of unweighted UniFrac distances for cecum samples after 8 wk of the HF/HS diet (blue $=A \times B 19$, red $=$ SWR, green $=$ cross-fostered SWR). Significant differences: (*) $P<0.05,\left({ }^{* * *}\right) \quad P<0.0001$, according to unpaired two-tailed Student's $t$-test. See also Supplemental Figure 2.

A. muciniphila (HF/HS). After 1 wk of gavage, all mice were put on $\mathrm{HF} / \mathrm{HS}$ diet for four additional weeks. After $5 \mathrm{wk}$ of gavage, we observed that mice given $A$. muciniphila showed significantly improved metabolic parameters. Figure 3A shows that body weight and total body fat, including all fat depots examined, were significantly reduced in A. muciniphila-treated mice. Plasma lipid levels showed substantial decreases in total cholesterol and triglycerides (Fig. 3B). Most striking were the effects on insulin resistance, with dramatically decreased levels of both glucose and insulin (Fig. 3B). Our data are consistent with the correlations observed among the HMDP as well as recent findings (Everard et al. 2013).

In addition to metabolic changes, the administration of $A$. muciniphila altered the gut microbiota composition (Fig. 3C). Thus, using both chow and HF/HS diets, A. muciniphila-treated mice clustered separately from mice that received heat-inactivated bacteria (Supplemental Fig. 3A,B). This difference was evident at the phylum level, showing significant shifts between two dominant phyla, Bacteoridetes and Firmicutes (Supplemental Fig. 3C). Surprisingly, we did not observe significant differences in the total

abundance of A. muciniphila, perhaps because DNA from heatkilled bacteria was also present.

\section{Genome-wide association (GWAS) analysis of loci controlling} gut microbiota in mice

Next, we aimed to obtain evidence for specific interactions between gut microbiota and host genetics. Rather than using linkage analysis, as is traditional in mouse genetics, we employed association across the HMDP strains, since the resolution of mapping is one or two orders improved (Bennett et al. 2010). Such association analysis has now been used to identify novel genes which were subsequently validated in a number of cases (Farber et al. 2011; Lavinsky et al. 2015; Parks et al. 2015; Rau et al. 2015), but given the structure of the inbred mouse population, there is some potential for long-range linkage disequilibrium. The proportion of each common taxon was treated as an individual trait, and association analyses were performed with 198,431 informative SNPs spaced throughout the mouse genome using a mixed-model algorithm that corrects for population structure (Kang et al. 2008). The threshold for genome-wide significance was based on simulation and permutations as previously described (Farber et al. 2011). Altogether, seven genome-wide significant loci $\left(P<4 \times 10^{-6}\right)$ were found to be associated with common genera (Fig. 4; Supplemental Table 6). Loci ranged from $800 \mathrm{~kb}$ to $3 \mathrm{Mb}$ in size and in most cases contained several genes within a linkage disequilibrium block. The majority of these significant associations were detected with members of the classes Clostridia (Lachospiraceae, Ruminococcacea, and Bacilli), and most exhibited similar associations in both sexes (Supplemental Table 6). In order to test whether the GWAS results were inflated by the effect that multiple animals from the same strain were housed in the same cage, we performed GWAS using only one animal per strain. Even with the reduced sample size, we were able to detect GWAS associations in the same regions (Supplemental Table 6), albeit with reduced significance. We have carried out expression profiling of adipose and liver of the HMDP strains when maintained on HF/HS diets and used the data to identify cis expression quantitative trait loci (eQTL). These provide a useful means of prioritizing candidate genes at the relevant loci since they provide evidence of functional variation (Civelek and Lusis 2014). The significant cis-eQTLs at each of the GWAS loci are shown in Supplemental Figure 5 and Supplemental Table 7. Here, we focus on those genera that show strong correlation with clinical traits, as discussed above; additional loci are described in detail in the Supplemental Material.

For Roseburia spp., we identified significant associations spanning 2.6 Mb on Chromosome 15 (Fig. 4A; Supplemental Table 6). The same region showed a significant association with subcutaneous fat mass on a HF/HS diet $\left(P<10^{-7}\right)$ (Supplemental Fig. $\left.4 \mathrm{~A}\right)$, a clinical trait that is also positively correlated with the abundance of Roseburia spp. $\left(r=0.25, P=3.9 \times 10^{-10}\right)$ (Table 2). Global gene expression in epididymal adipose tissue and liver showed a significant cis-eQTL between the peak SNP (rs31843241) and transcript levels of the Kif21a, Lrrk2, and Irak4 genes (Table 2; Fig. 5A; Supplemental Fig. 5; Supplemental Table 7). The expression of Irak4, a gene involved in the initiation of the innate immune response, was correlated with the abundance of Roseburia spp. and HOMA-IR, suggesting a causal relationship (Fig. 5B,C).

Ruminococcus gnavus exhibited genome-wide significant association to a locus on Chromosome 19 (Fig. 4B; Supplemental Table 6). The peak SNP (rs30796836, $P=8.37 \times 10^{-7}$ ) has a significant ciseQTL with the transcript levels of the Osbp (oxysterol binding 

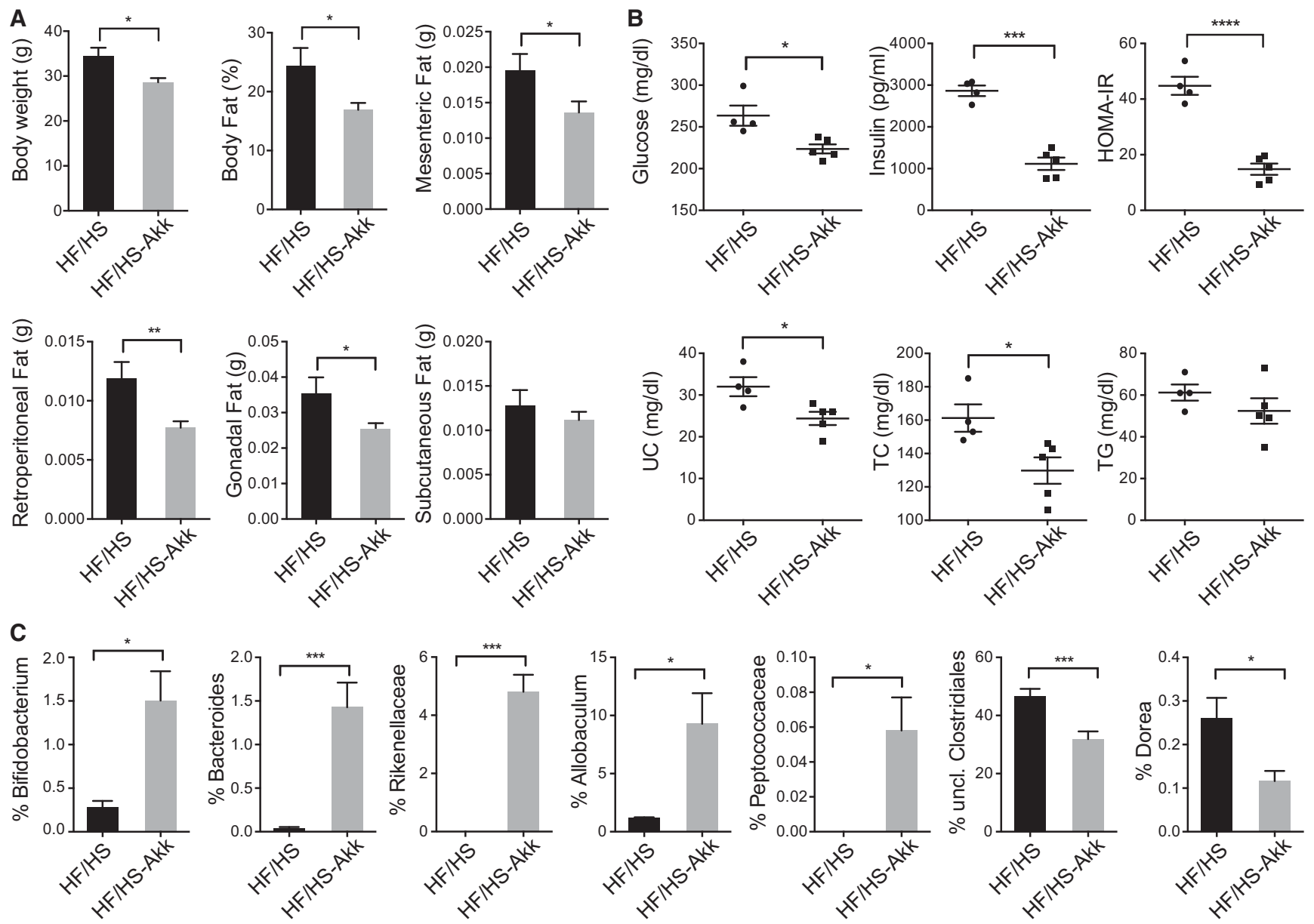

Figure 3. Akkermansia muciniphila treatment reduces obesity and metabolic syndrome traits in mice fed a HF/HS diet. $(A)$ Total body weight, body fat, mesenteric, retroperitoneal, gonadal, and subcutaneous fat depot weights (g per $100 \mathrm{~g}$ body weight) in mice treated by oral gavage with live or heat-inactivated $A$. muciniphila and fed a HF/HS diet $(n=5)$. (B) Glucose, insulin, HOMA-IR, unesterified cholesterol (UC), total cholesterol (TC), and triglycerides (TG) levels. (C) Relative abundance of bacterial genera between different treatment groups. Data are shown as means \pm SD. Significant differences: $(*) P<$ $0.05,(* *) P<0.01,(* *) P<0.001,(* * *) P<0.0001$, with unpaired two-tailed Student's $t$-test.

protein) gene in adipose tissue of HF/HS-fed mice (females: $P=1.51 \times 10^{-12}$; males: $P=2.54 \times 10^{-10}$ ), and the abundance of Ruminococcus gnavus negatively correlated with expression of Osbp $(r=-0.36 ; \quad P=0.00014)$ (Table 2; Supplemental Fig. 5; Supplemental Table 7).

Finally, we detected significant associations for the abundance of A. muciniphila on Chromosomes 7 (rs33129247; $P=$ $2.59 \times 10^{-6}$ ) and 2 (rs27323290, $P=6.67 \times 10^{-6}$ ) (Figs. 4C, 6A; Supplemental Table 6). The peak SNP on Chromosome 7 (rs33129247) was also associated with triglyceride levels $(P=$ $\left.6.47 \times 10^{-9}\right)$ and gonadal fat $\left(P=7.44 \times 10^{-7}\right)$ (Table 2; Fig. 6B; Supplemental Fig. 4B). Strong candidates for this locus are $I g f 1 r$ and $N r 2 f 2$ genes, since both have been shown to play a role in glucose and insulin regulation (Ueki et al. 2006; Garg et al. 2011). The Chromosome 2 locus contains Ctnnbl1, a gene implicated in obesity (Liu et al. 2008; Tan et al. 2014) and two interesting candidates, bactericidal/permeability-increasing protein (Bpi) and lipopolysaccharide binding protein $(L p b)$. Ctnnbl1 also showed a significant association with food intake $\left(P=1.17 \times 10^{-9}\right)$ and total weight after $8 \mathrm{wk}$ on the HF/HS diet $\left(P=5.8 \times 10^{-8}\right)$ (Table 2). The Lbp and Ctnnbl1 genes both have significant cis-eQTLs in adipose and liver (Table 2; Fig. 6C; Supplemental Fig. 5; Supplemental
Table 7) and are associated with body fat percentage increase and insulin levels (Fig. 6D,E).

\section{Discussion}

We previously showed that inbred strains of mice differ dramatically in their response to a high-fat, high-sucrose diet (Parks et al. 2013). Based on the large body of evidence indicating that gut microbiota can influence metabolic traits (Backhed et al. 2004, 2007; Turnbaugh et al. 2006, 2009; Ridaura et al. 2013), we hypothesized that the dietary response was dictated in part by differences in gut microbiota. We showed that different inbred strains differ strikingly in the composition of gut microbiota and provided evidence that the variation is determined in part by the host genetic background. Consistent with our hypothesis, we showed that cross-fostering between two strains of mice affected dietary response to the high-fat, high-sucrose diet. By correlating microbiota composition with dietary response among the HMDP inbred strains, we were able to identify several candidate microbiota influencing dietary response. We chose one of these, A. muciniphila, to examine using gavage with the cultured microbe and observed striking effects on weight gain, adiposity, plasma lipids, 
A

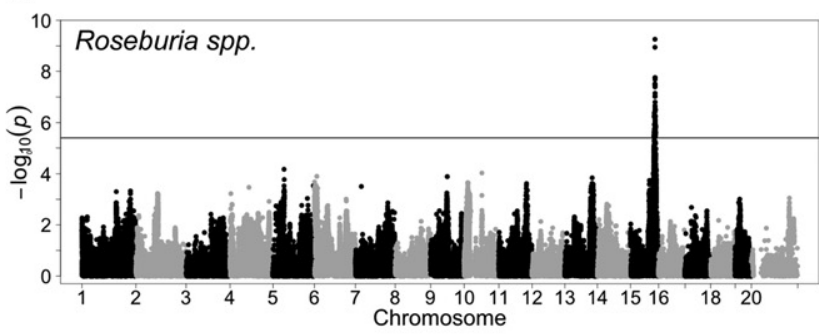

B

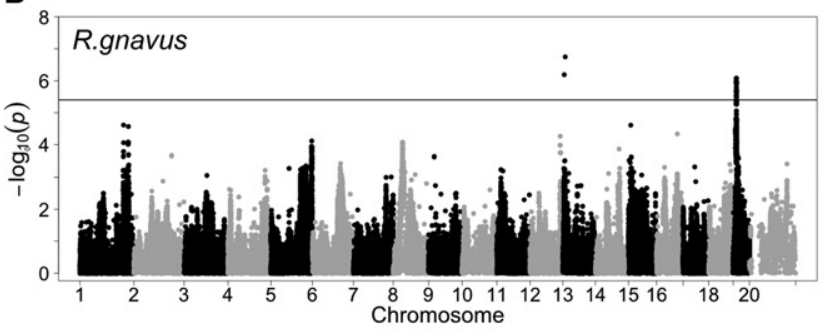

C

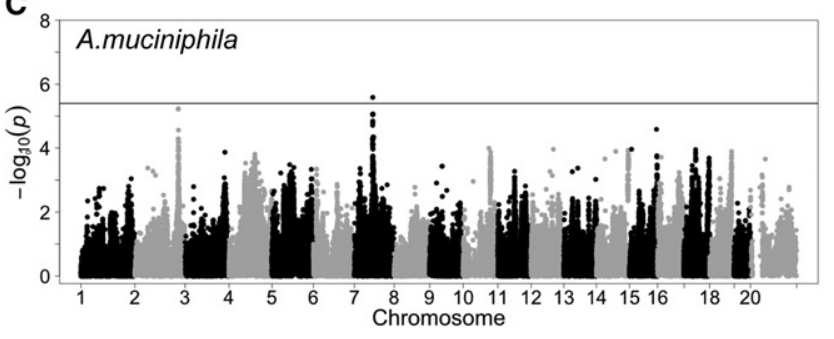

D

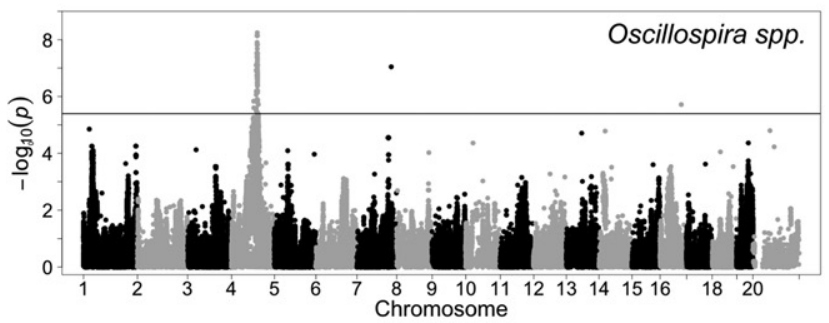

E

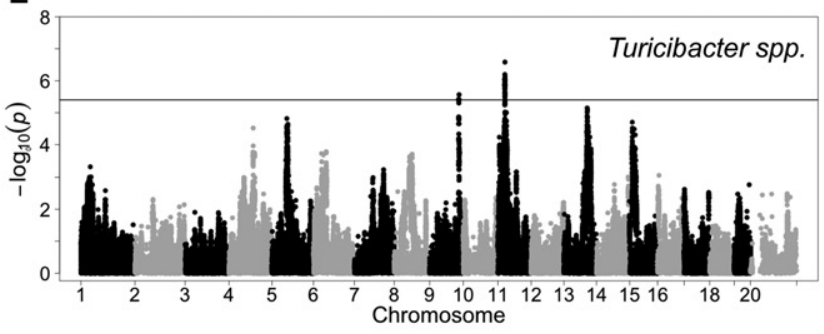

Figure 4. Genome-wide association mapping of gut microbiota genera in the HMDP: (A) Roseburia spp., (B) R. gnavus, (C) A. muciniphila, (D) Oscillospira spp., (E) Turicibacter spp. Association was performed using the FaST-LMM algorithm (Lippert et al. 2011) following correction for population structure using $\sim 200,000$ filtered SNPs genotyped in all strains. The horizontal line indicates the threshold for genome-wide significance $\left(P<4 \times 10^{-6}\right)$. See also Supplemental Table 6.

and insulin resistance. Finally, to help identify novel host-microbiota interactions, we have mapped loci controlling certain microbiota taxa. We discuss each of these findings in turn below.

Experimental studies have shown that the host genetic background can influence gut microbiota composition. For example, mice with mutations affecting inflammatory signaling or diabetes differ in microbiota composition from their wild-type littermates (Henao-Mejia et al. 2012; Peng et al. 2014). However, the importance of common genetic variants in contributing to the composition of the gut microbiota is unclear. While twin pairs and related individuals share gut microbiota to a greater extent than unrelated individuals, early studies did not find a statistically significant difference in gut microbiota sharing in monozygotic (MZ) and dizygotic (DZ) twins. However a recent study with 416 twin pairs demonstrated that MZ twins have greater overall microbial community similarities than DZ twin pairs and identified several microbial taxa with relative abundances that differ depending on host genetics (Goodrich et al. 2014). Studies using genetic crosses of mice, where the environment can be controlled, also suggest that host genetics can significantly alter gut microbiota composition (Benson et al. 2010; McKnite et al. 2012; Srinivas et al. 2013).

Heritability represents the fraction of variation that is attributable to genetic variation and is a relative value that depends on the environment and the degree to which the population varies. Traditionally, heritability has been estimated using pedigrees in outbred populations or by comparing monozygotic versus di- zygotic twins. In mice, heritability is generally estimated by analyzing genetic crosses, but for studies of gut microbiota, this is confounded by the fact that there is physical transmission of "seed" microbiota from generation to generation (Ubeda et al. 2012). To circumvent this problem, we used a SNP-based approach to determine relatedness (Yang et al. 2010) rather than a family-based approach. All of the inbred strains constituting the HMDP are separated from one another by many generations (Silver 1995) and thus are unlikely to share microbiota as a result of physical transmission. Our results indicate a high degree of heritability of the major groups of microbiota in mice, ranging from $\sim 0.3$ to $>0.5$, although we note certain caveats in our approach (see Results). This high heritability presumably results from the fine tuning of a symbiotic relationship that has co-evolved for millions of years. Among the likely contributing factors are differences in immunoglobulin and antibacterial molecules secreted into the gut lumen (Wen et al. 2008; Vijay-Kumar et al. 2010; Shulzhenko et al. 2011), differences in the mucosal gut structure (Sommer et al. 2014; Wlodarska et al. 2014), and differences in bile acid metabolism (Ryan et al. 2014).

Previous studies have shown that certain large effect mutations affecting inflammatory signaling or metabolic traits can significantly affect microbiota composition and that, in some cases, these can be transmitted by transplantation of gut microbiota from such mice (Henao-Mejia et al. 2012; Peng et al. 2014). Here, we have examined whether common variations in gut microbiota 


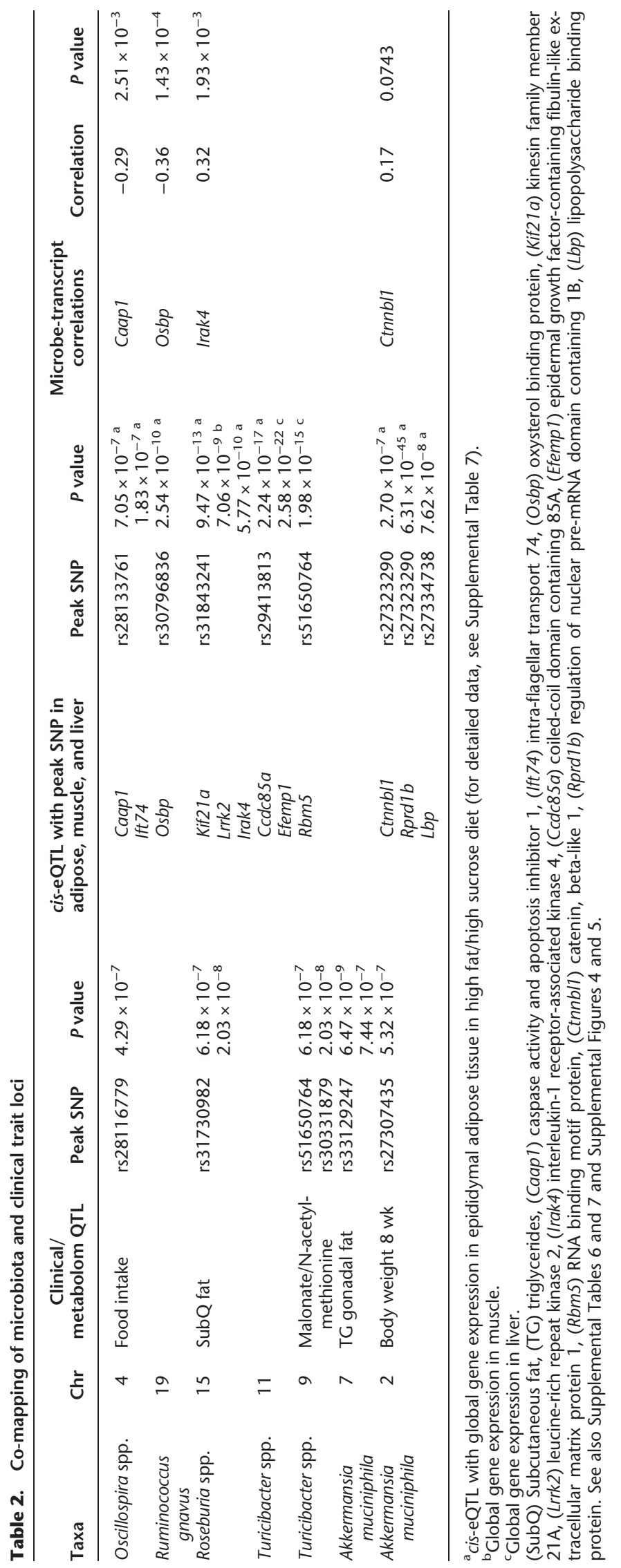


A
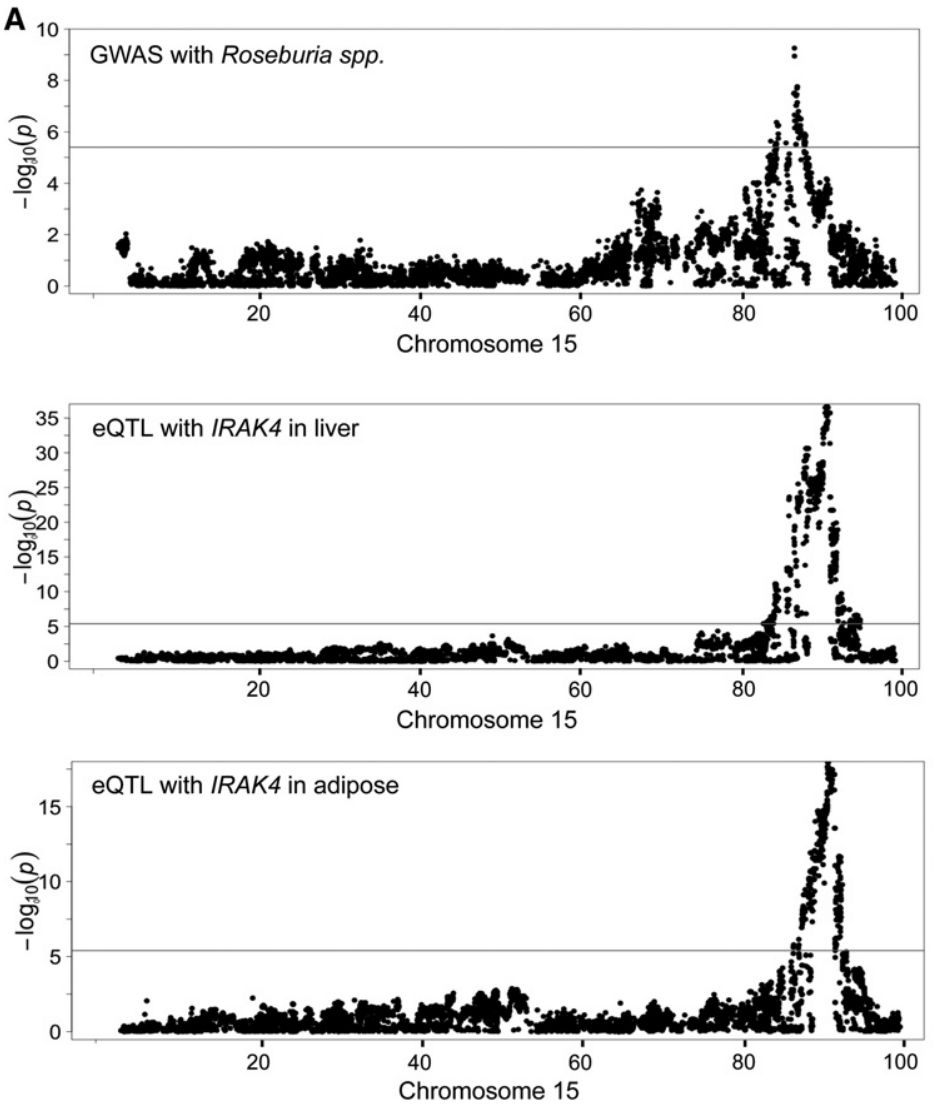

B

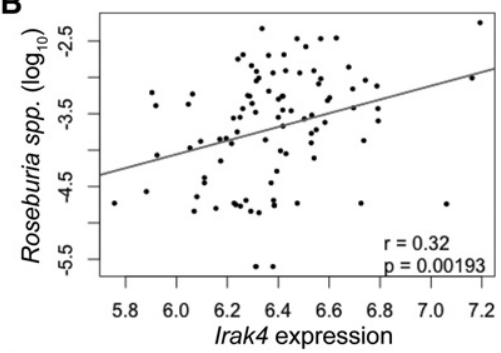

C

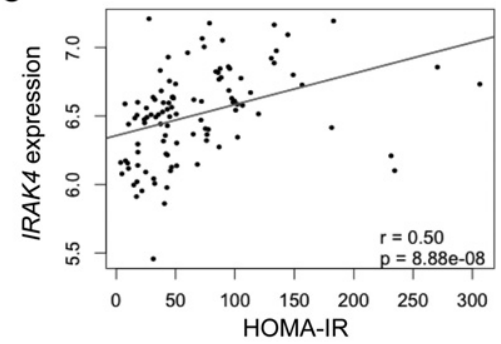

Figure 5. Chromosome 15 locus for abundance of genus Roseburia spp. (A) Overlapping genome-wide significant associations with the abundance of Roseburia spp. and liver and adipose eQTLs of the Irak4 gene in HMDP mice fed a HF/HS diet. The horizontal line indicates the threshold for genome-wide significance $\left(P<4 \times 10^{-6}\right)$. $(B, C)$ Correlations of Irak4 adipose gene expression with the relative abundance of Roseburia spp. and HOMA-IR in the HMDP mice. ( $r$ ) Biweight midcorrelation, $(p) P$ value. See also Supplemental Tables 6 and 7.

are also causally involved in metabolic traits. To test this possibility, we chose two inbred strains, $\mathrm{A} \times \mathrm{B} 19$ and SWR, that differ strikingly in the response to a HF/HS diet for cross-fostering studies. When male SWR mice cross-fostered by A×B19 dams were subjected to the HF/HS diet, they gained $\sim 8 \%$ in total body fat as compared to $\sim 2 \%$ for SWR, while A×B19 gained $\sim 25 \%$ (Fig. 2C). Thus, while the majority of the response was dictated by the host genetic background, the gut microbiota did contribute significantly. Human gut microbiota exhibit more diversity and quantitative variation than what we have observed among common mouse strains, suggesting that a significant fraction of variance in obesity and insulin resistance in human populations is due to microbiota composition. Conceivably, this could explain some of the "missing heritability" observed in GWAS. We used correlation analysis to identify candidate microbiota contributing to the response to the HF/HS diet. Several genera were found to be strongly associated with traits such as body fat, plasma lipids, and insulin resistance, including some, such as Roseburia spp. and A. muciniphila, that have previously been implicated in metabolic traits. We chose $A$. muciniphila, a mucin-degrading, gramnegative anaerobe, to examine its potential response to our dietary challenge. We administered by oral gavage either live or heat-killed bacteria to strain $\mathrm{A} \times \mathrm{B} 19$ male mice for $1 \mathrm{wk}$ and then began the $\mathrm{HF} / \mathrm{HS}$ challenge, continuing to administer the live or heat-killed bacteria for a total of $5 \mathrm{wk}$. Significant differences were observed between the groups in body fat gain, plasma lipid levels, and insu- lin resistance. We noted significant correlations between the abundances of certain taxa across the panel of strains (data not shown), providing information about microbiota community interactions.

Finally, we used the HMDP to perform high-resolution mapping of loci contributing to microbiota abundance. Using association analysis, we identified seven significant loci for five out of 17 common genus level taxa. Most of the loci were observed in both males and females, supporting the conclusion that they are true positives. The loci contain a number of strong candidate genes based on the literature, functional variants, and correlations with clinical and molecular traits (see Supplemental Material). The Chromosome 15 locus for Roseburia spp. contains the Irak4 gene, which is involved in signaling innate immune responses from Toll-like receptors (Flannery and Bowie 2010; Liu et al. 2011). Mice deficient in Irak4 expression are more susceptible to viral and bacterial infections (Suzuki et al. 2002), and Irak4 has previously been associated with gut microbiota composition in a subset of BxD RI strains (McKnite et al. 2012). The A. muciniphila locus in Chromosome 2 contains two closely linked genes, Bpi and $L b p$. Both bind to bacterial lipopolysaccharide (LPS) and elicit immune responses by presenting LPS to CD14 and TLR4 and signaling the acute-phase immunological response (Muta and Takeshige 2001). Bpi acts as an endogenous antibiotic protein with potent killing activity against gram-negative bacteria (Wittmann et al. 2008).

Our data constitute a resource for the further dissection of mechanistic host-gut microbiota interactions. We have identified 
A
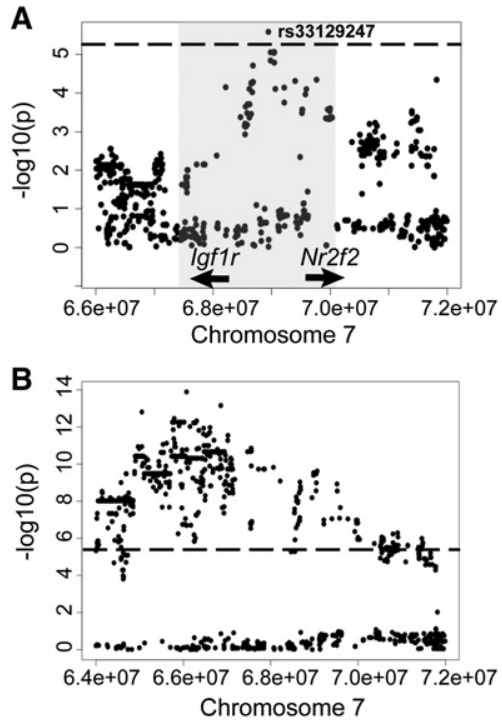

C
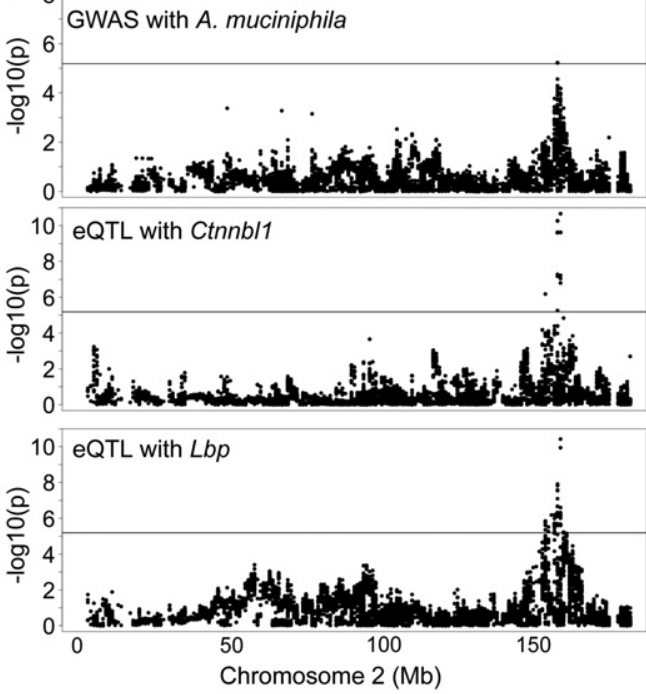
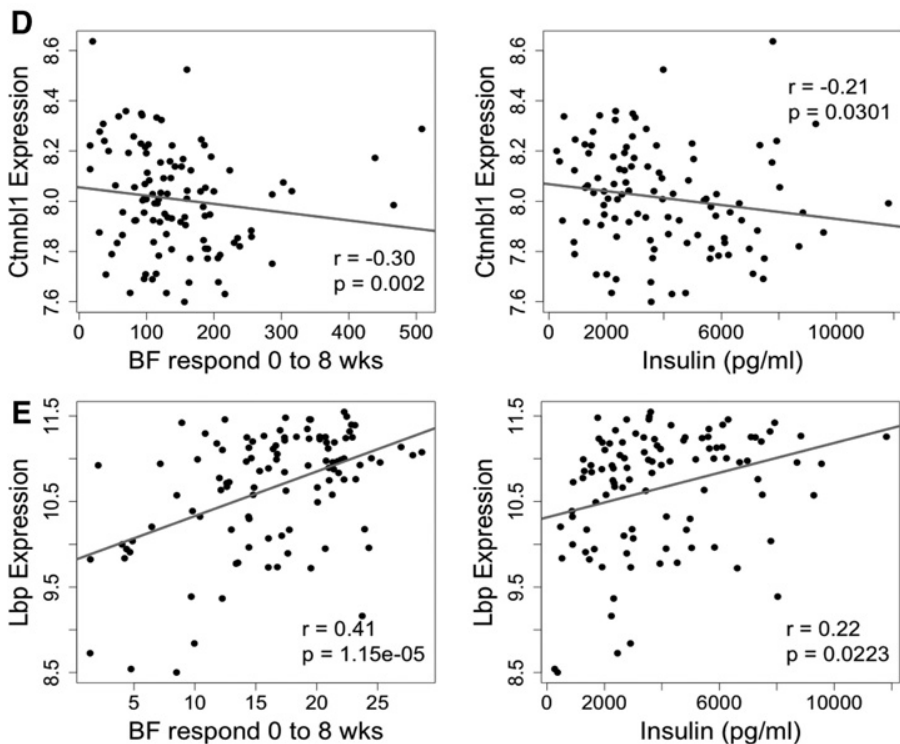

Figure 6. Chromosome 2 and 7 loci for abundance of $A$. muciniphila. (A) Locus plot for genome-wide significant association of $A$. muciniphila abundance to a Chromosome 7 locus, indicating the LD block (shaded in gray) and peak SNP rs33129247. Locations of candidate genes are indicated. (B) Locus plot for association with TG (triglyceride) at the Chromosome 7 locus. See also Supplemental Tables 6 and 7. (C) Chromosome 2 locus showing overlapping associations with the abundance of A. muciniphila and cis-eQTLs of the Ctnnbl1 and Lbp genes in adipose. (D) Correlation of epididymal adipose gene expression of Ctnnb/1 with body fat and insulin levels after $8 \mathrm{wk}$ of the HF/HS diet. (E) Correlation of epididymal adipose gene expression of $L b p$ with body fat response and insulin levels after $8 \mathrm{wk}$ of the HF/HS diet. (BF) Body fat, $(r)$ biweight midcorrelation, $(p) P$ value.

a number of highly significant associations between gut microbiota and clinical traits, and the loci reported here provide a means of identifying novel host factors controlling gut microbiota abundances.

\section{Methods}

Sample collection and study design

All mice were obtained from The Jackson Laboratory and were bred at UCLA for two or more generations for use in this study. Briefly, until 8 wk of age mice were maintained on a chow diet (Ralson Purina Company) and then placed on a high-fat, high-sucrose diet (Research Diets D12266B) for an additional 8 wk (Parks et al.
2013). Samples were obtained from the cecum of 599 mice from 113 strains, with an average of six mice per strain (327 males and 297 females) (Supplemental Table 1). Mice from different strains and genders were housed in separate cages but in the same room throughout the study. Cecum and fecal samples were snap-frozen with liquid nitrogen and stored at $-80^{\circ} \mathrm{C}$. The animal protocol for the study was approved by the Institutional Care and Use Committee (IACUC) at the University of California, Los Angeles.

\section{Sample preparation and sequencing of 16S rRNA genes}

Microbial DNA was extracted using the PowerSoil DNA Isolation Kit (MO BIO Laboratories). Amplification and sequencing of the $\mathrm{V} 4$ hypervariable region of the $16 \mathrm{~S}$ rRNA gene was performed

\section{Genome Research}

www.genome.org 
using the validated, region-specific bacterial primers $515 \mathrm{~F}$ and 806R according to previously described methods (Caporaso et al. 2012) optimized for the Illumina MiSeq platform. The reverse amplification primer contained a 12-bp Golay error-correcting barcode sequence, and amplicons were generated in triplicate using 5 Prime Hot MasterMix (Fischer Scientific). The PCR conditions consisted of an initial denaturation step of $94^{\circ} \mathrm{C}$ for $3 \mathrm{~min}$; $35 \mathrm{cy}$ cles of $94^{\circ} \mathrm{C}$ for $45 \mathrm{sec}, 50^{\circ} \mathrm{C}$ for $30 \mathrm{sec}$, and $72^{\circ} \mathrm{C}$ for $90 \mathrm{sec}$, followed by $72^{\circ} \mathrm{C}$ for $5 \mathrm{~min}$. Replicate amplicons were quantified with a Quant-iT PicoGreen dsDNA Assay kit (Life Technologies), pooled (200 ng from 96 samples), and purified using with the UltraClean PCR Clean-up kit (MO BIO Laboratories). Highthroughput sequencing analysis of bacterial rRNA genes was performed on the purified, pooled sample using the Illumina MiSeq platform (Illumina).

De-multiplexing $16 \mathrm{~S}$ rRNA gene sequences, quality control, and operational taxonomic unit binning were performed using the open source pipeline Quantitative Insights Into Microbial Ecology (QIIME) version 1.7.0 (Caporaso et al. 2010; Bokulich et al. 2013). The total number of sequencing reads was $13,805,813$ (an average of 23,048 reads per sample) with an average length of 153-bp reads. Sequences were binned into OTUs based on 97\% identity using UCLUST (Edgar 2010) against the Greengenes reference database (McDonald et al. 2012). Each sample's sequences were rarefied to 7000 reads to reduce the effect of sequencing depth. Seven samples were omitted from further analysis due to insufficient sequence coverage, yielding 592 samples.

Microbial composition at each taxonomic level was defined using the summarize_taxa function in QIIME. Prior to genomewide association analysis, taxa at any taxon present in fewer than $75 \%$ of samples was discarded, yielding a total of 43 common taxa from different taxonomic levels (three phyla, five classes, six orders, 12 families, and 17 genus level taxa). The relative abundance of each taxon was calculated by dividing the sequences pertaining to a specific taxon by the total number of bacterial sequences for that sample.

\section{Heritability calculations}

Heritability was estimated using a linear mixed with the EMMAX software model (Kang et al. 2010). In this approach, the phenotypes (in this case, the relative abundances) are assumed to be generated by genetic and environmental components. The assumption behind the linear mixed model approach is that the covariance of the genetic component of the phenotypic data is proportional to the kinship or genetic similarity matrix between the animals. The analysis provides estimates of $\sigma_{g}^{2}$ and $\sigma_{e}^{2}$, the variances corresponding to the genetic and environmental component, respectively. The heritability is then the fraction of the variance accounted for by the genetics or

$$
\frac{\sigma_{g}^{2}}{\sigma_{g}^{2}+\sigma_{e}^{2}}
$$

and is computed for each relative abundance. We note that the kinship matrix must be standardized for these estimates to be consistent with the classical definition of heritability (Kostem and Eskin 2013; Speed and Balding 2015). A standardized kinship matrix has a mean along the diagonal of 1 and a sum of 0 .

\section{Clinical traits}

Body composition, food intake, and blood and plasma assays were as previously described (Parks et al. 2013, 2015). Briefly, mice were measured for total body fat mass and lean mass using nuclear magnetic resonance (NMR) using the Bruker minispec with software from Eco Medical Systems. Blood was collected from mice following fasting for $4-5 \mathrm{~h}$, and plasma was isolated by centrifugation in Microtainer tubes with EDTA (Becton Dickinson). Plasma glucose levels were measured using a Beckman Glucose Analyzer 2 (Beckman Instruments). Plasma total cholesterol, HDL cholesterol, free cholesterol, triglycerides, and free fatty acid concentrations were determined by enzymatic assays employing colorimetric endpoints as described previously (Hedrick et al. 1993). Insulin levels and HOMA-IR were determined as previously described (Castellani et al. 2008).

\section{Cross-fostering study}

Within $24 \mathrm{~h}$ of birth, the pups from SWR females were removed from birthing cages and placed with A×B19/PgnJ mothers. Pups were weaned on postnatal day 21 , and at $8 \mathrm{wk}$ of age mice were placed on a high-fat/high-sucrose diet (Research Diets D12266B) for an additional $8 \mathrm{wk}$. Controls from both strains were fostered with different mothers from the same strain.

\section{Akkermansia muciniphila gavage}

A. muciniphila (ATCC BAA-835) was grown in a Columbia broth medium supplemented with $0.05 \%$ hog gastric Mucin type III (Sigma) under anaerobic conditions (Ganesh et al. 2013). Cells were harvested in late logarithmic phase by centrifugation at $6000 \mathrm{rpm}$ in a tabletop Fisher centrifuge at room temperature and resuspended in 0.05 volume sterile anaerobic PBS containing $25 \%$ glycerol to a concentration of $7.2 \times 10^{10}$ per mL prior to storage at $-80^{\circ} \mathrm{C}$. For gavage, anaerobic cell suspensions were diluted 10 -fold in PBS. The sterile anaerobic PBS ( $\mathrm{pH} 7$ ) was supplemented with $0.05 \%$ cysteine $\mathrm{HCl}$, degassed with $\mathrm{N}_{2}$, sealed in serum bottles with butyl rubber stoppers under anaerobic conditions provided by a gas phase of $1.8 \mathrm{~atm} \mathrm{~N} / \mathrm{CO}_{2}(80: 20, \mathrm{vol} / \mathrm{vol})$.

A. muciniphila was administrated to 10 -wk-old $\mathrm{A} \times \mathrm{B} 19$ male mice ( $n=5$ per group), housed in groups of $2-3$ mice per cage, by oral gavage at a dose $1.44 \times 10^{9} \mathrm{cfu} / 0.2 \mathrm{~mL}$ suspended in sterile anaerobic PBS (HF-Akk). Treatment was $5 \mathrm{~d}$ per week for $5 \mathrm{wk}$. Control groups were treated with an equivalent volume of heat-inactivated A. muciniphila. After the first week of A. muciniphila treatment, all mice were placed on the HF/HS diet for an additional $4 \mathrm{wk}$.

\section{Association analyses}

Association analyses of taxa were performed using the Factored Spectrally Transformed Linear Mixed Models (FaST-LMM) algorithm adjusting for population structure and using gender as a covariate (Kang et al. 2008; Lippert et al. 2011). To achieve a normal distribution, the sequence counts for each taxonomic bin were Arcsine-transformed. A total of 198,431 informative SNPs (minorallele frequency $>5 \%$; missing genotype rate $<10 \%$ ) spaced throughout the genome were used. For genome-wide significance, we used a $P$ value threshold $<4 \times 10^{-6}$, based on permutation and simulation and which roughly corresponds to a Bonferroni correction (Bennett et al. 2010; Farber et al. 2011). In some cases, multiple animals from the same strain were housed together, and in order to rule out the possibility that GWAS results were inflated because strains shared similar microbiota compositions due to physical transfer, we also performed GWAS choosing a single sample from each strain at random $(n=113)$. Linkage disequilibrium (http://pngu.mgh.harvard. edu/ purcell/plink/) boundaries were determined by calculating SNP correlations and visualizing $r^{2}>0.8$ in Haploview.

\section{Expression QTL analysis}

To help identify candidate genes at loci associated with taxa abundances, we carried out global expression analysis of epididymal 
adipose and liver tissue in male and female mice (16 wk old) fed a HF/HS diet as described (Parks et al. 2015). Isolated RNA (two mice per strain) was analyzed for global gene expression using Affymetrix HT_MG-430A arrays and filtered as described (Bennett et al. 2010). Microarray data are available in the Genome Expression Omnibus (GEO; http://www.ncbi.nlm.nih.gov/geo/) under accession number GSE64770. The loci controlling transcript levels were mapped with FaST-LMM and are referred to as expression quantitative trait loci. Loci are defined as cis if the peak SNP mapped within $1 \mathrm{Mb}$ of gene position ( $P$ value threshold $\left.<1.4 \times 10^{-3}\right)$.

\section{Statistics}

All correlations involving bacterial relative abundance were performed using biweight midcorrelation, which is robust to outliers (Wilcox 2005). The statistical cutoff of $P=0.1$ after false discovery rate (FDR) correction for multiple comparisons was used to define statistical significance for correlations. Statistical analyses were performed using GraphPad Prism. Data are expressed as mean \pm SEM, and significance was set at a two-tailed $P$ value $<0.05$.

\section{Data access}

$16 \mathrm{~S}$ rRNA sequencing data generated for this study have been submitted to the NCBI Sequence Read Archive (SRA; http://www.ncbi. nlm.nih.gov/sra/) under accession number SRP059760. The summary tables for both genders are posted on our website (systems. genetics.ucla.edu/data/hmdp2) with the link called "Download high-fat microbiota vs. clinical trait correlation table" and can also be found in Supplemental Material (Supplemental Table 8).

\section{Acknowledgments}

We thank Hannah Qi, Zhiqiang Zhou, Judy Wu, Tieyan Han, and Richard Davis for expert assistance with mouse experiments, and Jonathan T. Furuta for growing A. muciniphila. This work was supported by National Institutes of Health (NIH) grants HL028481, HL30568, and DK094311 to A.J.L. and UCLA Iris Cantor Women's Health Center and UCLA CTSI to T.A.D. E.O. was supported by a MOBILITAS Postdoctoral Research Grant (MJD252) and FP7 grant no. 330381. B.W.P. was supported by NIH training grant T32-HD07228.

Author contributions: A.J.L, E.E., and T.A.D. supervised the study. R.K. provided comments and discussion. E.O. and B.W.P. oversaw collection of samples. E.O., W.S., and B.E. collected microbial data. R.G. prepared A. muciniphila for gavage experiment. E.O. performed the analysis with contribution from J.W.J.J., E.Y.K., C. P., and R.K. E.O., A.J.L., and E.E. prepared the manuscript with comments from B.E., T.A.D., and R.K.

\section{References}

Backhed F, Ding H, Wang T, Hooper LV, Koh GY, Nagy A, Semenkovich CF, Gordon JI. 2004. The gut microbiota as an environmental factor that regulates fat storage. Proc Natl Acad Sci 101: 15718-15723.

Backhed F, Manchester JK, Semenkovich CF, Gordon JI. 2007. Mechanisms underlying the resistance to diet-induced obesity in germ-free mice. Proc Natl Acad Sci 104: 979-984.

Bennett BJ, Farber CR, Orozco L, Kang HM, Ghazalpour A, Siemers N, Neubauer M, Neuhaus I, Yordanova R, Guan B, et al. 2010. A high-resolution association mapping panel for the dissection of complex traits in mice. Genome Res 20: 281-290.

Benson AK, Kelly SA, Legge R, Ma F, Low SJ, Kim J, Zhang M, Oh PL, Nehrenberg D, Hua K, et al. 2010. Individuality in gut microbiota composition is a complex polygenic trait shaped by multiple environmental and host genetic factors. Proc Natl Acad Sci 107: 18933-18938.
Bokulich NA, Subramanian S, Faith JJ, Gevers D, Gordon JI, Knight R, Mills DA, Caporaso JG. 2013. Quality-filtering vastly improves diversity estimates from Illumina amplicon sequencing. Nat Methods 10: 57-59.

Caporaso JG, Kuczynski J, Stombaugh J, Bittinger K, Bushman FD, Costello EK, Fierer N, Pena AG, Goodrich JK, Gordon JI, et al. 2010. QIIME allows analysis of high-throughput community sequencing data. Nat Methods 7: 335-336.

Caporaso JG, Lauber CL, Walters WA, Berg-Lyons D, Huntley J, Fierer N, Owens SM, Betley J, Fraser L, Bauer M, et al. 2012. Ultra-high-throughput microbial community analysis on the Illumina HiSeq and MiSeq platforms. ISME J 6: 1621-1624.

Carmody RN, Gerber GK, Luevano JM Jr, Gatti DM, Somes L, Svenson KL, Turnbaugh PJ. 2015. Diet dominates host genotype in shaping the murine gut microbiota. Cell Host Microbe 17: 72-84.

Castellani LW, Nguyen CN, Charugundla S, Weinstein MM, Doan CX, Blaner WS, Wongsiriroj N, Lusis AJ. 2008. Apolipoprotein AII is a regulator of very low density lipoprotein metabolism and insulin resistance. J Biol Chem 283: 11633-11644.

Civelek M, Lusis AJ. 2014. Systems genetics approaches to understand complex traits. Nat Rev Genet 15: 34-48.

Costello EK, Lauber CL, Hamady M, Fierer N, Gordon JI, Knight R. 2009. Bacterial community variation in human body habitats across space and time. Science 326: 1694-1697.

Derrien M, Van Baarlen P, Hooiveld G, Norin E, Muller M, de Vos WM. 2011. Modulation of mucosal immune response, tolerance, and proliferation in mice colonized by the mucin-degrader Akkermansia muciniphila. Front Microbiol 2: 166

Devkota S, Wang Y, Musch MW, Leone V, Fehlner-Peach H, Nadimpalli A, Antonopoulos DA, Jabri B, Chang EB. 2012. Dietary-fat-induced taurocholic acid promotes pathobiont expansion and colitis in $1 l 10^{-1-}$ mice. Nature 487: 104-108.

Eckburg PB, Bik EM, Bernstein CN, Purdom E, Dethlefsen L, Sargent M, Gill SR, Nelson KE, Relman DA. 2005. Diversity of the human intestinal microbial flora. Science 308: 1635-1638.

Edgar RC. 2010. Search and clustering orders of magnitude faster than BLAST. Bioinformatics 26: 2460-2461.

Everard A, Belzer C, Geurts L, Ouwerkerk JP, Druart C, Bindels LB, Guiot Y, Derrien M, Muccioli GG, Delzenne NM, et al. 2013. Cross-talk between Akkermansia muciniphila and intestinal epithelium controls diet-induced obesity. Proc Natl Acad Sci 110: 9066-9071.

Falconer DS, Mackay TFC. 1996. Introduction to quantitative genetics, 4th ed. Longman, New York.

Farber CR, Bennett BJ, Orozco L, Zou W, Lira A, Kostem E, Kang HM, Furlotte N, Berberyan A, Ghazalpour A, et al. 2011. Mouse genome-wide association and systems genetics identify Asxl2 as a regulator of bone mineral density and osteoclastogenesis. PLoS Genet 7: e1002038.

Flannery S, Bowie AG. 2010. The interleukin-1 receptor-associated kinases: critical regulators of innate immune signalling. Biochem Pharmacol 80: 1981-1991.

Ganesh BP, Klopfleisch R, Loh G, Blaut M. 2013. Commensal Akkermansia muciniphila exacerbates gut inflammation in Salmonella typhimurium-infected gnotobiotic mice. PLoS One 8: e74963.

Garg N, Thakur S, McMahan CA, Adamo ML. 2011. High fat diet induced insulin resistance and glucose intolerance are gender-specific in IGF1R heterozygous mice. Biochem Biophys Res Commun 413: 476-480.

Goodrich JK, Waters JL, Poole AC, Sutter JL, Koren O, Blekhman R, Beaumont M, Van Treuren W, Knight R, Bell JT, et al. 2014. Human genetics shape the gut microbiome. Cell 159: 789-799.

Hedrick CC, Castellani LW, Warden CH, Puppione DL, Lusis AJ. 1993. Influence of mouse apolipoprotein A-II on plasma lipoproteins in transgenic mice. J Biol Chem 268: 20676-20682.

Henao-Mejia J, Elinav E, Jin C, Hao L, Mehal WZ, Strowig T, Thaiss CA, Kau AL, Eisenbarth SC, Jurczak MJ, et al. 2012. Inflammasome-mediated dysbiosis regulates progression of NAFLD and obesity. Nature 482: $179-185$.

Human Microbiome Project Consortium. 2012. Structure, function and diversity of the healthy human microbiome. Nature 486: 207-214.

Kang HM, Zaitlen NA, Wade CM, Kirby A, Heckerman D, Daly MJ, Eskin E. 2008. Efficient control of population structure in model organism association mapping. Genetics 178: 1709-1723.

Kang HM, Sul JH, Service SK, Zaitlen NA, Kong SY, Freimer NB, Sabatti C, Eskin E. 2010. Variance component model to account for sample structure in genome-wide association studies. Nat Genet 42: 348-354.

Kostem E, Eskin E. 2013. Improving the accuracy and efficiency of partitioning heritability into the contributions of genomic regions. Am J Hum Genet 92: 558-564.

Lavinsky J, Crow AL, Pan C, Wang J, Aaron KA, Ho MK, Li Q, Salehide P, Myint A, Monges-Hernadez M, et al. 2015. Genome-wide association study identifies Nox3 as a critical gene for susceptibility to noise-induced hearing loss. PLoS Genet 11: e1005094.

\section{Genome Research}

www.genome.org 
Lippert C, Listgarten J, Liu Y, Kadie CM, Davidson RI, Heckerman D. 2011. FaST linear mixed models for genome-wide association studies. Nat Methods 8: 833-835.

Liu YJ, Liu XG, Wang L, Dina C, Yan H, Liu JF, Levy S, Papasian CJ, Drees BM, Hamilton JJ, et al. 2008. Genome-wide association scans identified CTNNBL1 as a novel gene for obesity. Hum Mol Genet 17: 1803-1813.

Liu Z, Lee J, Krummey S, Lu W, Cai H, Lenardo MJ. 2011. The kinase LRRK2 is a regulator of the transcription factor NFAT that modulates the severity of inflammatory bowel disease. Nat Immunol 12: 1063-1070.

Lynch M, Walsh JB. 1998. Genetics and analysis of quantitative traits. Sinauer Associates, Sunderland, MA.

McCafferty J, Muhlbauer M, Gharaibeh RZ, Arthur JC, Perez-Chanona E, Sha W, Jobin C, Fodor AA. 2013. Stochastic changes over time and not founder effects drive cage effects in microbial community assembly in a mouse model. ISME J 7: 2116-2125.

McDonald D, Price MN, Goodrich J, Nawrocki EP, DeSantis TZ, Probst A, Andersen GL, Knight R, Hugenholtz P. 2012. An improved Greengenes taxonomy with explicit ranks for ecological and evolutionary analyses of bacteria and archaea. ISME J 6: 610-618.

McKnite AM, Perez-Munoz ME, Lu L, Williams EG, Brewer S, Andreux PA Bastiaansen JW, Wang X, Kachman SD, Auwerx J, et al. 2012. Murine gut microbiota is defined by host genetics and modulates variation of metabolic traits. PLoS One 7: e39191.

Million M, Angelakis E, Paul M, Armougom F, Leibovici L, Raoult D. 2012. Comparative meta-analysis of the effect of Lactobacillus species on weight gain in humans and animals. Microb Pathog 53: 100-108.

Musso G, Gambino R, Cassader M. 2011. Interactions between gut microbiota and host metabolism predisposing to obesity and diabetes. Annu Rev Med 62: 361-380.

Muta T, Takeshige K. 2001. Essential roles of CD14 and lipopolysaccharidebinding protein for activation of toll-like receptor (TLR) 2 as well as TLR4: reconstitution of TLR2- and TLR4-activation by distinguishable ligands in LPS preparations. Eur J Biochem 268: 4580-4589.

Orozco LD, Bennett BJ, Farber CR, Ghazalpour A, Pan C, Che N, Wen P, Qi HX, Mutukulu A, Siemers N, et al. 2012. Unraveling inflammatory responses using systems genetics and gene-environment interactions in macrophages. Cell 151: 658-670.

Parks BW, Nam E, Org E, Kostem E, Norheim F, Hui ST, Pan C, Civelek M, Rau CD, Bennett BJ, et al. 2013. Genetic control of obesity and gut microbiota composition in response to high-fat, high-sucrose diet in mice. Cell Metab 17: 141-152.

Parks BW, Sallam T, Mehrabian M, Psychogios N, Hui ST, Norheim F, Castellani LW, Rau CD, Pan C, Phun J, et al. 2015. Genetic architecture of insulin resistance in the mouse. Cell Metab 21: 334-346.

Peng J, Narasimhan S, Marchesi JR, Benson A, Wong FS, Wen L. 2014. Long term effect of gut microbiota transfer on diabetes development. I Autoimmun 53: 85-94.

Rau CD, Wang J, Avetisyan R, Romay MC, Martin L, Ren S, Wang Y, Lusis AJ. 2015. Mapping genetic contributions to cardiac pathology induced by $\beta$-adrenergic stimulation in mice. Circ Cardiovasc Genet 8: 40-49.

Ridaura VK, Faith JJ, Rey FE, Cheng J, Duncan AE, Kau AL, Griffin NW, Lombard V, Henrissat B, Bain JR, et al. 2013. Gut microbiota from twins discordant for obesity modulate metabolism in mice. Science 341: 1241214.

Ryan KK, Tremaroli V, Clemmensen C, Kovatcheva-Datchary P, Myronovych A, Karns R, Wilson-Perez HE, Sandoval DA, Kohli R, Backhed F, et al. 2014. FXR is a molecular target for the effects of vertical sleeve gastrectomy. Nature 509: 183-188.

Shulzhenko N, Morgun A, Hsiao W, Battle M, Yao M, Gavrilova O, Orandle M, Mayer L, Macpherson AJ, McCoy KD, et al. 2011. Crosstalk between B lymphocytes, microbiota and the intestinal epithelium governs immunity versus metabolism in the gut. Nat Med 17: 1585-1593.

Silver LM. 1995. Mouse genetics: concepts and applications. Oxford University Press, New York.

Sommer F, Adam N, Johansson ME, Xia L, Hansson GC, Backhed F. 2014. Altered mucus glycosylation in core $1 \mathrm{O}$-glycan-deficient mice affects microbiota composition and intestinal architecture. PLoS One 9: e85254.

Speed D, Balding DJ. 2015. Relatedness in the post-genomic era: Is it still useful? Nat Rev Genet 16: 33-44.
Srinivas G, Moller S, Wang J, Kunzel S, Zillikens D, Baines JF, Ibrahim SM. 2013. Genome-wide mapping of gene-microbiota interactions in susceptibility to autoimmune skin blistering. Nat Commun 4: 2462.

Suzuki N, Suzuki S, Duncan GS, Millar DG, Wada T, Mirtsos C, Takada H, Wakeham A, Itie A, Li S, et al. 2002. Severe impairment of interleukin1 and Toll-like receptor signalling in mice lacking IRAK-4. Nature 416: 750-756.

Tan LJ, Zhu H, He H, Wu KH, Li J, Chen XD, Zhang JG, Shen H, Tian Q, Krousel-Wood M, et al. 2014. Replication of 6 obesity genes in a metaanalysis of genome-wide association studies from diverse ancestries. PLoS One 9: e96149.

Tims S, Derom C, Jonkers DM, Vlietinck R, Saris WH, Kleerebezem M, de Vos WM, Zoetendal EG. 2013. Microbiota conservation and BMI signatures in adult monozygotic twins. ISME J 7: 707-717.

Turnbaugh PJ, Ley RE, Mahowald MA, Magrini V, Mardis ER, Gordon JI. 2006. An obesity-associated gut microbiome with increased capacity for energy harvest. Nature 444: 1027-1031.

Turnbaugh PJ, Hamady M, Yatsunenko T, Cantarel BL, Duncan A, Ley RE, Sogin ML, Jones WJ, Roe BA, Affourtit JP, et al. 2009. A core gut microbiome in obese and lean twins. Nature 457: 480-484.

Ubeda C, Lipuma L, Gobourne A, Viale A, Leiner I, Equinda M, Khanin R, Pamer EG. 2012. Familial transmission rather than defective innate immunity shapes the distinct intestinal microbiota of TLR-deficient mice. $J$ Exp Med 209: 1445-1456.

Ueki K, Okada T, Hu J, Liew CW, Assmann A, Dahlgren GM, Peters JL, Shackman JG, Zhang M, Artner I, et al. 2006. Total insulin and IGF-I resistance in pancreatic $\beta$ cells causes overt diabetes. Nat Genet 38 : 583-588.

Vaahtovuo J, Munukka E, Korkeamaki M, Luukkainen R, Toivanen P. 2008. Fecal microbiota in early rheumatoid arthritis. J Rheumatol 35: 1500-1505.

Verdam FJ, Fuentes S, de Jonge C, Zoetendal EG, Erbil R, Greve JW, Buurman WA, de Vos WM, Rensen SS. 2013. Human intestinal microbiota composition is associated with local and systemic inflammation in obesity. Obesity 21: E607-E615.

Vijay-Kumar M, Aitken JD, Carvalho FA, Cullender TC, Mwangi S, Srinivasan S, Sitaraman SV, Knight R, Ley RE, Gewirtz AT. 2010. Metabolic syndrome and altered gut microbiota in mice lacking Tolllike receptor 5. Science 328: 228-231.

Wang Z, Klipfell E, Bennett BJ, Koeth R, Levison BS, Dugar B, Feldstein AE, Britt EB, Fu X, Chung YM, et al. 2011. Gut flora metabolism of phosphatidylcholine promotes cardiovascular disease. Nature 472: 57-63.

Wen L, Ley RE, Volchkov PY, Stranges PB, Avanesyan L, Stonebraker AC, Hu C, Wong FS, Szot GL, Bluestone JA, et al. 2008. Innate immunity and intestinal microbiota in the development of Type 1 diabetes. Nature 455: 1109-1113.

Wilcox RR. 2005. Introduction to robust estimation and hypothesis testing. Elsevier/Academy Press, Amsterdam, The Netherlands.

Wittmann I, Schonefeld M, Aichele D, Groer G, Gessner A, Schnare M. 2008. Murine bactericidal/permeability-increasing protein inhibits the endotoxic activity of lipopolysaccharide and gram-negative bacteria. $J$ Immunol 180: 7546-7552.

Wlodarska M, Thaiss CA, Nowarski R, Henao-Mejia J, Zhang JP, Brown EM, Frankel G, Levy M, Katz MN, Philbrick WM, et al. 2014. NLRP6 inflammasome orchestrates the colonic host-microbial interface by regulating goblet cell mucus secretion. Cell 156: 1045-1059.

Wu GD, Chen J, Hoffmann C, Bittinger K, Chen YY, Keilbaugh SA, Bewtra M, Knights D, Walters WA, Knight R, et al. 2011. Linking long-term dietary patterns with gut microbial enterotypes. Science 334: 105-108.

Yang J, Benyamin B, McEvoy BP, Gordon S, Henders AK, Nyholt DR, Madden PA, Heath AC, Martin NG, Montgomery GW, et al. 2010. Common SNPs explain a large proportion of the heritability for human height. Nat Genet 42: 565-569.

Yoshimoto S, Loo TM, Atarashi K, Kanda H, Sato S, Oyadomari S, Iwakura Y, Oshima K, Morita H, Hattori M, et al. 2013. Obesity-induced gut microbial metabolite promotes liver cancer through senescence secretome. Nature 499: 97-101.

Received May 8, 2015; accepted in revised form August 7, 2015. 


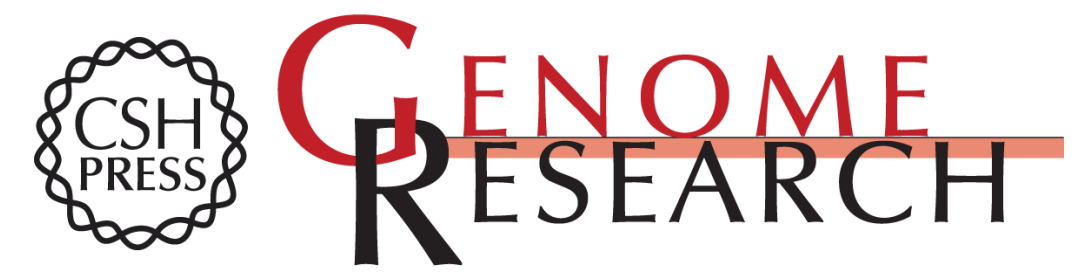

\section{Genetic and environmental control of host-gut microbiota interactions}

Elin Org, Brian W. Parks, Jong Wha J. Joo, et al.

Genome Res. 2015 25: 1558-1569 originally published online August 10, 2015

Access the most recent version at doi:10.1101/gr.194118.115

Supplemental Material

References

Open Access

Creative Commons

License

Email Alerting Service
http://genome.cshlp.org/content/suppl/2015/08/17/gr.194118.115.DC1

This article cites 65 articles, 17 of which can be accessed free at: http://genome.cshlp.org/content/25/10/1558.full.html\#ref-list-1

Freely available online through the Genome Research Open Access option.

This article, published in Genome Research, is available under a Creative Commons License (Attribution 4.0 International), as described at http://creativecommons.org/licenses/by/4.0/.

Receive free email alerts when new articles cite this article - sign up in the box at the top right corner of the article or click here.

\section{Affordable, Accurate Sequencing.}

